\title{
Colonoscopy and flexible sigmoidoscopy practice patterns in Ontario: A population-based study
}

\author{
Susan E Schultz MA MSc ${ }^{1}$, Chris Vinden MD ${ }^{1,2}$, Linda Rabeneck MD MPH ${ }^{1,3,4,5}$
}

SE Schultz, C Vinden, L Rabeneck. Colonoscopy and flexible sigmoidoscopy practice patterns in Ontario: A populationbased study. Can J Gastroenterol 2007;21(7):431-434.

OBJECTIVE: To conduct a population-based study on the provision of large bowel endoscopic services in Ontario.

METHODS: Data from the following databases were analyzed: the Ontario Health Insurance Plan, the Institute for Clinical Evaluative Sciences Physicians Database and Statistics Canada. The flexible sigmoidoscopy and colonoscopy rates per 10,000 persons ( 50 to 74 years of age) by region between April 1, 2001, and March 31, 2002, were calculated, as well as the numbers and types of physicians who performed each procedure.

RESULTS: In 2001/2002, a total of 172,108 colonoscopies and 43,400 flexible sigmoidoscopies were performed in Ontario for all age groups. The colonoscopy rate was approximately five times that of flexible sigmoidoscopy; rates varied from 463.1 colonoscopies per 10,000 people in the north to 286.8 colonoscopies per 10,000 people in the east. Gastroenterologists in all regions tended to perform more procedures per physician, but because of the large number of general surgeons, the total number of procedures performed by each group was almost the same.

CONCLUSION: Population-based rates of colonoscopies and flexible sigmoidoscopies are low in Ontario, as are the procedure volumes of approximately one-quarter of physicians.

\section{Les types de pratique de coloscopies et de sigmoïdoscopies flexibles en Ontario : Une étude en population générale}

\begin{abstract}
OBJECTIF : Mener une étude en population générale au sujet de la prestation des services endoscopiques du gros intestin en Ontario. MÉTHODOLOGIE : On a analysé les données des bases de données suivantes : la Régie d'assurance-maladie de l'Ontario, la base de données des médecins de l'Institut de recherche en services de santé et Statistique Canada. On a calculé les taux de sigmoïdoscopies flexibles et de coloscopies pour 10000 habitants (de 50 à 74 ans) selon la région entre le $1^{\text {er }}$ avril 2001 et le 31 mars 2002, ainsi que le nombre et le type de médecins qui ont effectué chaque intervention.

RÉSULTATS : En 2001-2002, on a exécuté 172108 coloscopies et 43400 sigmoïdoscopies flexibles en Ontario, dans tous les groupes d'âge. Le taux de coloscopies était environ cinq fois plus élevé que celui de sigmoïdoscopies flexibles. Les taux variaient entre 463,1 coloscopies pour 10000 habitants au Nord à 286,8 coloscopies pour 10000 habitants à l'Est. Les gastroentérologues de toutes les régions avaient tendance à effectuer plus d'interventions par médecin, mais en raison du grand nombre de chirurgiens généralistes, chaque groupe a effectué un total d'interventions presque similaire.

CONCLUSION : Les taux de coloscopies et de sigmoïdoscopies en population générale sont faibles en Ontario, de même que le volume d'interventions d'environ le quart des médecins.
\end{abstract}

Key Words: Colonoscopy; Flexible sigmoidoscopy; Practice patterns

A large body of evidence shows that screening for colorectal Acancer (CRC) can reduce both cancer incidence and mortality (1-7). In spite of this, recently published data from Ontario indicate that only a fraction of the population in the target age range of 50 to 74 years is being screened, regardless of the screening modality used $(8,9)$.

Screening rates are affected by a number of different patient and physician factors. One of these is uptake - whether physicians recommend screening for their patients and whether patients accept the recommendation. Another important factor is access to screening services. In the United States, studies (10) have assessed the provision of endoscopic services. However, few such studies have been performed in Canada (11)

The purpose of the present study was to investigate physicians' provision of colonoscopy and flexible sigmoidoscopy in Ontario by examining the rates and distributions of procedures by physician specialty and by region. We also investigated the overall supply and distribution of physicians performing these procedures.

\section{METHODS}

Data for colonoscopy and flexible sigmoidoscopy procedures performed from April 1, 2001, to March 31, 2002, for people 50 to 74 years of age (the screen-eligible age group) in Ontario were analyzed. Ontario had an estimated population of 11.9 million in 2001. Of this population, 2.7 million Ontarians were in the screen-eligible age group.

Information about colonoscopies and flexible sigmoidoscopies in Ontario during 2001/2002 was obtained from the Ontario Health Insurance Plan (OHIP) database, a database of all billings by fee-for-service physicians and shadow billings for many physicians on alternate payment plans. The database does not include billings by physicians working in health service organizations, community health centres or those on salary who do not use shadow billing. This group comprises approximately $2 \%$ of all physicians in Ontario, most of whom are family physicians. Because in several geographic regions (Frontenac County, Kenora, and Rainy River Districts), the proportion of physicians providing endoscopic procedures on a non-fee-for-service basis without shadow

${ }^{1}$ Institute for Clinical Evaluative Sciences, Toronto; ${ }^{2}$ Department of Surgery, University of Western Ontario, London; ${ }^{3}$ Toronto Sunnybrook

Regional Cancer Centre; ${ }^{4}$ Department of Medicine; ${ }^{5}$ Department of Health Policy, Management and Evaluation, University of Toronto,

Toronto, Ontario

Correspondence: Dr Linda Rabeneck, Toronto Sunnybrook Regional Cancer Centre, 2075 Bayview Avenue, T2-025, Toronto,

Ontario M4N 3M5. Telephone 416-480-4825, fax 416-480-5804, e-mail linda.rabeneck@sunnybrook.ca

Received for publication April 26, 2006. Accepted September 11, 2006 
TABLE 1

Population (50 to 74 years of age) and endoscopy rates by region in Ontario, 2001/2002

\begin{tabular}{|c|c|c|c|c|c|}
\hline \multirow[b]{2}{*}{ Region } & \multirow[b]{2}{*}{ Population } & \multicolumn{2}{|c|}{ Procedures, $\mathbf{n}$} & \multicolumn{2}{|c|}{$\begin{array}{c}\text { Endoscopy rate } \\
\text { per } 10,000 \text { persons }\end{array}$} \\
\hline & & cs & FS & CS & FS \\
\hline Central east & 447,061 & 26,469 & 4608 & 439.2 & 74.0 \\
\hline Central south & 283,162 & 16,005 & 3422 & 322.9 & 60.6 \\
\hline Central west & 441,276 & 22,544 & 7272 & 373.0 & 80.6 \\
\hline East & 378,835 & 17,228 & 6385 & 286.8 & 89.9 \\
\hline North & 225,639 & 14,856 & 2341 & 463.1 & 62.7 \\
\hline Southwest & 362,711 & 22,912 & 6183 & 366.4 & 78.9 \\
\hline Toronto & 570,713 & 52,021 & 13,175 & 426.9 & 84.0 \\
\hline Ontario (overall) & $2,709,397$ & 172,108 & 43,400 & 385.7 & 77.7 \\
\hline
\end{tabular}

CS Colonoscopy; FS Flexible sigmoidoscopy

billings was deemed to be too large to yield reliable estimates of activity in the region, data from these regions were excluded from the analysis.

Since procedures performed for screening purposes and diagnostic reasons are indistinguishable because they have the same billing code and reimbursement, the present study examined all colonoscopies and flexible sigmoidoscopies, not just those performed for CRC screening. Because physicians in Ontario use separate fee codes for each segment of the colon examined, the distance that the colonoscope was inserted could be determined. Flexible sigmoidoscopy was defined as endoscopy up to, but not beyond, the splenic flexure (OHIP codes Z580, Z555 and E740). Colonoscopy was defined as endoscopy to the hepatic flexure and beyond (OHIP codes Z555 and E740 and E741 and/or E747 and/or E705).

Information about each physician's billing location and specialty was obtained from the Institute for Clinical Evaluative Sciences' physician database, which comprises information from the OHIP Corporate Provider Database and from the Ontario Physician Human Resources Data Centre. Population estimates by age, sex and county were obtained from Statistics Canada (Statistics Canada, Annual Demographic Statistics, Category \# 91-213-XMP).

\section{RESULTS}

Colonoscopy and flexible sigmoidoscopy rates, as well as physician supply

Table 1 shows the age- and sex-adjusted rates for colonoscopy and flexible sigmoidoscopy in Ontario for 2001/2002 among the screen-eligible population. The colonoscopy rate was approximately five times that of flexible sigmoidoscopy. The regional variation was also wide, because colonoscopy rates ranged from 463.1 procedures per 10,000 persons aged 50 to 74 years, in the north to 286.8 procedures per 10,000 persons in the east. The range for flexible sigmoidoscopy was proportionally similar (the highest rate was $50 \%$ more than the lowest).

Colonoscopy and flexible sigmoidoscopy rates are based on a number of factors, two of which are the supply of physicians in the region and the proportion of physicians who perform the procedures. Information about these factors can be found in Table 2. Some areas, such as the central east, had a relatively small number of physicians per 100,000 persons but a higher proportion who performed endoscopy. In other areas, the situation was reversed. The combination of these two factors, namely, the supply of physicians performing colonoscopy and flexible sigmoidoscopy, is shown in Figure 1. Supply was highest in the southwest and lowest in the central east; the latter was due to low overall supply of specialists.

Distribution of colonoscopy and flexible sigmoidoscopy by physician specialty and region

In 2001/2002, a total of 172,108 colonoscopies and 43,400 flexible sigmoidoscopies were performed in Ontario (all age groups combined). As Figure 2 shows, gastroenterologists performed the greatest proportion of procedures, closely followed by general surgeons. Only $3 \%$ and $6 \%$ of flexible sigmoidoscopies and colonoscopies, respectively, were performed by internal medicine specialists, and less than $5 \%$ of either procedure was performed by other physicians, including general practitioners or family physicians.

Figure 2 also illustrates how the pattern of service provision by physician specialty varied by region. In the north, for example, general surgeons performed over $60 \%$ of both procedures, whereas gastroenterologists performed the greatest proportion of procedures in the east and in Toronto.

\section{Colonoscopy and flexible sigmoidoscopy volumes by physician specialty}

The activity level of physicians who performed colonoscopy and flexible sigmoidoscopy in 2001/2002 also varied by region and by specialty. Table 3 examines the endoscopy volumes of gastroenterologists and general surgeons who performed a minimum of five procedures during the year. Compared with general surgeons, gastroenterologists in all regions tended to do more procedures per physician. However, because there were so many more general surgeons, the total number of procedures performed by each specialty was nearly the same. In addition to illustrating differences in physician activity levels between regions, Table 3 also shows the wide variability among physicians within regions.

\section{DISCUSSION}

The present study reports considerable variation in colonoscopy and flexible sigmoidoscopy rates by geographic region, by physician specialty and within specialty by region in Ontario. Rates for colonoscopy were highest in the north and central east, as well as the Toronto regions of Ontario, and were lowest in the east. Rates for flexible sigmoidoscopy across the province were only a fraction of those for colonoscopy. Overall, in Ontario, gastroenterologists or general surgeons performed $92 \%$ of these procedures, but the proportion of physicians performing large bowel endoscopy and the number of procedures performed varied by specialty and region. Variation in endoscopy rates among Ontario regions could not be explained by differences in either overall physician supply or supply of one particular physician specialty. Clearly other factors influenced endoscopy rates, which may have included patient factors, physician access to equipment and facilities needed to perform the procedures.

Some interesting differences can be noted between Ontario and the United States. For example, Brown et al (12), using survey data obtained during 1999/2000 from a national sample of American physicians, found that virtually all colonoscopies were performed by gastroenterologists and general surgeons. On the other hand, approximately two-thirds of all flexible sigmoidoscopies were performed by primary care physicians (family physicians and general internists). In Ontario, we 
TABLE 2

Physician supply in Ontario by region in 2001/2002

\begin{tabular}{|c|c|c|c|c|c|c|c|c|}
\hline & Central east & Central south & Central west & East & North & Southwest & Toronto & Ontario (overall) \\
\hline \multicolumn{9}{|c|}{ Number of physicians per 100,000 persons ( 50 to 74 years of age) } \\
\hline Gastroenterologists & 4.5 & 8.8 & 5.9 & 9.2 & 1.8 & 6.9 & 14.4 & 8.0 \\
\hline General surgeons & 18.3 & 29.0 & 19.0 & 24.3 & 27.9 & 27.0 & 33.1 & 25.9 \\
\hline Internists & 10.1 & 24.7 & 11.6 & 26.4 & 21.3 & 21.5 & 42.8 & 24.0 \\
\hline All others & 508.2 & 677.0 & 581.0 & 943.7 & 577.0 & 645.1 & 1184.3 & 775.9 \\
\hline \multicolumn{9}{|c|}{ Proportion of physicians performing $\geq 5$ colonoscopies in $2001 / 2002$} \\
\hline Gastroenterologists & 90.0 & 100.0 & 100.0 & 71.4 & 100.0 & 96.0 & 82.7 & 87.0 \\
\hline General surgeons & 61.0 & 48.8 & 53.6 & 40.2 & 63.5 & 56.1 & 40.2 & 49.0 \\
\hline Internists & 15.6 & 5.7 & 9.8 & 5.0 & 12.5 & 5.1 & 2.0 & 5.6 \\
\hline \multicolumn{9}{|c|}{ Proportion of physicians performing $\geq 5$ flexible sigmoidoscopies in $2001 / 2002$} \\
\hline Gastroenterologists & 95.0 & 92.0 & 100.0 & 71.4 & 100.0 & 88.0 & 82.7 & 85.7 \\
\hline General surgeons & 62.2 & 48.8 & 54.8 & 40.2 & 60.3 & 55.1 & 35.4 & 47.6 \\
\hline Internists & 17.8 & 4.3 & 7.8 & 4.0 & 12.5 & 3.8 & 2.4 & 5.3 \\
\hline
\end{tabular}

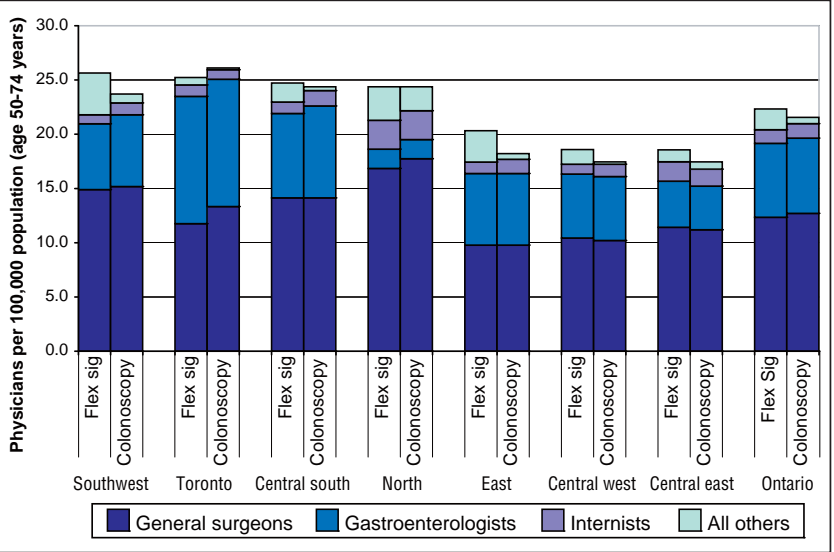

Figure 1) Supply of physicians performing colonoscopy and flexible sigmoidoscopy (Flex sig) in 2001/2002 by physician specialty group and region in Ontario

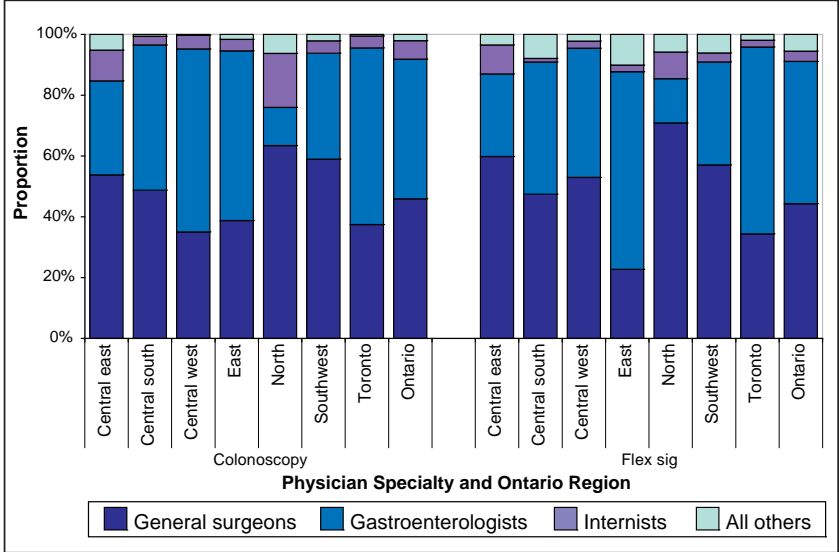

Figure 2) Proportional distribution of colonoscopies and flexible sigmoidoscopies (Flex sig) performed in 2001/2002 by physician specialty group and region in Ontario

\section{TABLE 3}

Median number of procedures per physician performed in 2001/2002 by physician specialty and Ontario region*

\begin{tabular}{|c|c|c|c|c|c|c|}
\hline \multirow[b]{3}{*}{ Region } & \multicolumn{6}{|c|}{ Median (interquartile range) number of procedures per physician ${ }^{\dagger}$} \\
\hline & \multicolumn{3}{|c|}{ Colonoscopies } & \multicolumn{3}{|c|}{ Flexible sigmoidoscopies } \\
\hline & Gastroenterologists & General surgeons & Both combined & Gastroenterologists & General surgeons & Both combined \\
\hline Central south & $291.0(141.0-501.0)$ & $148.0(89.0-307.0)$ & $182.0(97.0-362.0)$ & $58.5(29.0-84.0)$ & $34.0(14.0-53.0)$ & $40.5(20.0-63.0)$ \\
\hline Central west & $494.0(444.0-608.0)$ & $133.0(93.0 .0-257.0)$ & $301.0(121.0-470.0)$ & $100(32.0-169.0)$ & $67.0(28.0-127.0)$ & $75.5(31.0-134.5)$ \\
\hline East & $357.0(281.0-484.0)$ & $160.0(68.0-224.0)$ & $222.0(84.0-364.0)$ & $150.0(86.0-238.0)$ & $36.0(10.0-56.0)$ & $55.0(19.0-122.0)$ \\
\hline Southwest & $337.5(157.5-459.5)$ & $217.0(128.0-352.0$ & $237.0(141.0-381.0)$ & $83.5(35.0-154.0)$ & $46.5(21.0-88.0)$ & $53.5(23.5-98.5)$ \\
\hline Toronto & $459.0(330.0-578.0)$ & $187.0(51.5-289.0)$ & $297.0(132.0-513.0)$ & $71.0(33.0-144.0)$ & $34.0(17.0-103.0)$ & $46.5(22.0-121.0)$ \\
\hline Ontario & $424.5(291.0-558.5)$ & $192.0(91.5-310.5)$ & $257.0(130.0-432.5)$ & $74.0(33.0-150.0)$ & $38.0(17.0-76.0)$ & $47.0(20.0-99.0)$ \\
\hline
\end{tabular}

*The distribution is often skewed because a few physicians performed many procedures and many physicians performed a few procedures, thus, regional activity level was measured by the median number (interquartile range) of procedures; tIncludes only those who performed five procedures or more in $2001 / 2002-$ the overall category includes all physicians (including internists, general practitioners or family physicians, and others) who performed five procedures or more during the year; ${ }^{\ddagger}$ Estimates not reportable because of small cell sizes (ie, $n \leq 5$ )

found that family physicians, general internists and others performed approximately $8 \%$ of both procedures. The much smaller proportion of flexible sigmoidoscopies performed by family physicians and internists in Ontario than in the United States may be partially explained by the low reimbursement level for this procedure. In the United States, Lewis and Asch
(13) found that Medicare reimbursement was just barely adequate to cover the cost of providing office-based sigmoidoscopy. In Ontario, OHIP reimbursement for this procedure is only a fraction of that provided by Medicare, creating a very strong disincentive for family physicians who may otherwise be interested in providing this service in their offices (8). For 
colonoscopy, family physicians, internists and other physicians performed a greater proportion of procedures in Ontario than in the United States, perhaps because in areas where the supply of gastroenterologists was relatively low, other physicians were performing more colonoscopies. For example, in the north and central east regions of Ontario, almost 13\% of colonoscopies were performed by internists and $5 \%$ by family physicians.

Since 1992, the demand for colonoscopy has risen rapidly in Ontario; year-over-year increases in the numbers of procedures were $15 \%$ from 1999 to 2000 and over $17 \%$ from 2000 to 2001 (8). These marked increases in use were not confined to Ontario. Hilsden (11) reported a $147 \%$ increase in the number of colonoscopies performed in the province of Alberta (population of three million in 2001) between 1994 and 2001.

Evidence suggests that physicians who perform fewer than 100 procedures per year or who have performed fewer than 50 procedures in their lifetime are more likely to perform incomplete colonoscopies than those who performed higher

\section{REFERENCES}

1. Selby JV, Friedman GD, Quesenberry CP Jr, Weiss NS.

A case-control study of screening sigmoidoscopy and mortality from colorectal cancer. N Engl J Med 1992;326:653-7.

2. Mandel JS, Bond JH, Church TR, et al. Reducing mortality from colorectal cancer by screening for fecal occult blood. Minnesota Colon Cancer Control Study. N Engl J Med 1993;328:1365-71. (Erratum in 1993;329:672).

3. Winawer SJ, Zauber AG, Ho MN, et al. Prevention of colorectal cancer by colonoscopic polypectomy. The National Polyp Study Workgroup. N Engl J Med 1993;329:1977-81.

4. Hardcastle JD, Chamberlain JO, Robinson MH, et al. Randomised controlled trial of faecal-occult-blood screening for colorectal cancer. Lancet 1996;348:1472-7.

5. Kronberg O, Fenger C, Olsen J, Jorgensen OD, Sondergaard O. Randomised study of screening for colorectal cancer with faecal-occult-blood test. Lancet 1996;348:1467-71.

6. Mandel JS, Church TR, Ederer F, Bond JH. Colorectal cancer mortality: Effectiveness of biennial screening for fecal occult blood. J Natl Cancer Inst 1999;91:434-7.

7. Mandel JS, Church TR, Bond JH, et al. The effect of fecal occult-blood screening on the incidence of colorectal cancer. N Engl J Med 2000;343:1603-7. volumes (14). Low volumes are an issue in Ontario; according to our study, over $25 \%$ of physicians who performed colonoscopies in 2001/2002 performed fewer than 100 procedures.

The present study must be interpreted in light of its strengths and weaknesses. Because the data included covered almost the entire population of Ontario, the study avoided the potential selection bias that can occur when only selected sites or clinics are included and it enabled estimates of populationbased use. The study was limited by the impossibility of determining whether a procedure was performed for screening or diagnostic purposes. Thus, the rates of use reported here include all procedures and represent upper bounds for CRC screening.

\section{CONCLUSION}

The rates of colonoscopy and flexible sigmoidoscopy are low in Ontario; one-quarter of physicians perform low procedure volumes. As demand increases, additional resources will be required - especially to support an organized, population-based screening program. Addressing the issue of endoscopy quality among low-volume endoscopists will be important.

8. Vinden C, Schultz S, Rabeneck L. ICES research atlas: Use of large bowel procedures in Ontario. <http://www.ices.on.ca/file/ Large_Bowel_R_Atlas.pdf $>$ (Version current at February 26, 2007).

9. Rabeneck L, Paszat LF. A population-based estimate of the extent of colorectal cancer screening in Ontario. Am J Gastroenterol 2004;99:1141-4.

10. Lieberman DA, De Garmo PL, Fleischer DE, Eisen GM, Helfand M. Patterns of endoscopy use in the United States. Gastroenterology 2000;118:619-24.

11. Hilsden RJ. Patterns of use of flexible sigmoidoscopy, colonoscopy and gastroscopy: A population-based study in a Canadian province. Can J Gastroenterol 2004;18:213-9.

12. Brown ML, Klabunde CN, Mysliwiec P. Current capacity for endoscopic colorectal cancer screening in the United States: Data from the National Cancer Institute Survey of Colorectal Cancer Screening Practices. Am J Med 2003;115:129-33.

13. Lewis JD, Asch DA. Barriers to office-based screening sigmoidoscopy: Does reimbursement cover costs? Ann Intern Med 1999;130:525-30.

14. Wexner SD, Garbus JE, Singh JJ; SAGES Colonoscopy Study Outcomes Group. A prospective analysis of 13,580 colonoscopies. Reevaluation of credentialing guidelines. Surg Endosc 2001;15:251-61. 


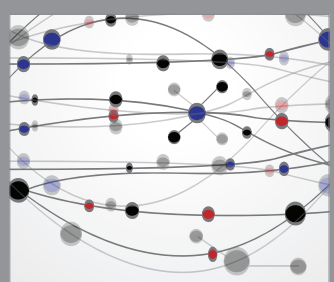

The Scientific World Journal
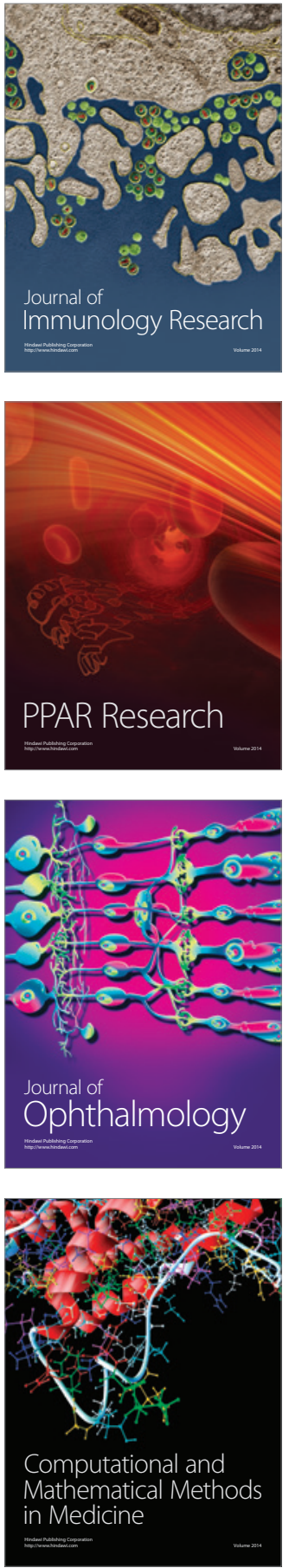

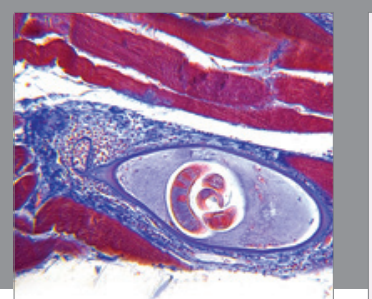

Gastroenterology Research and Practice

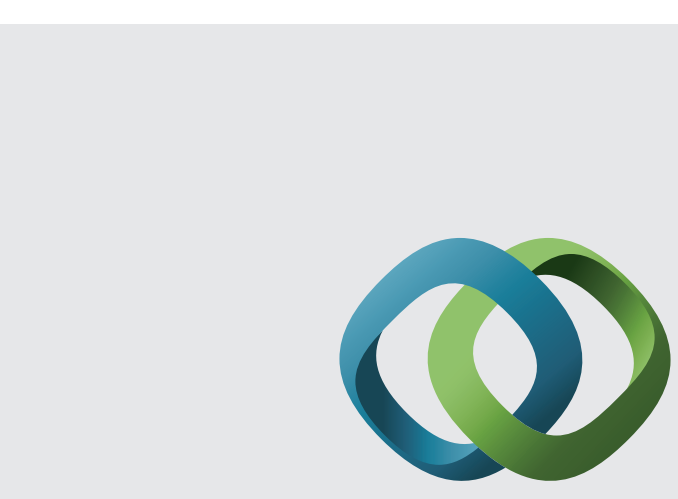

\section{Hindawi}

Submit your manuscripts at

http://www.hindawi.com
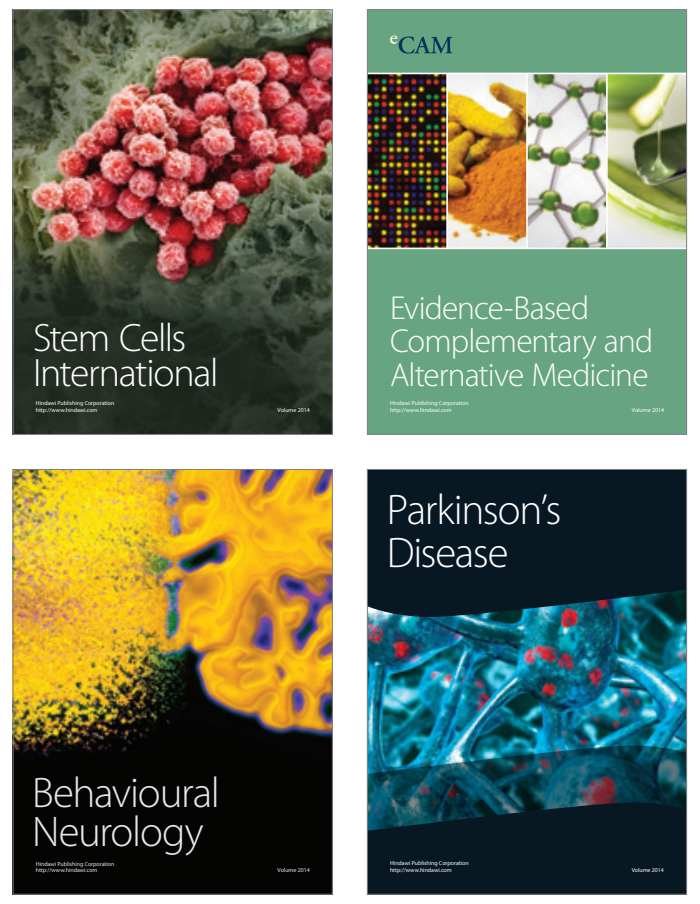
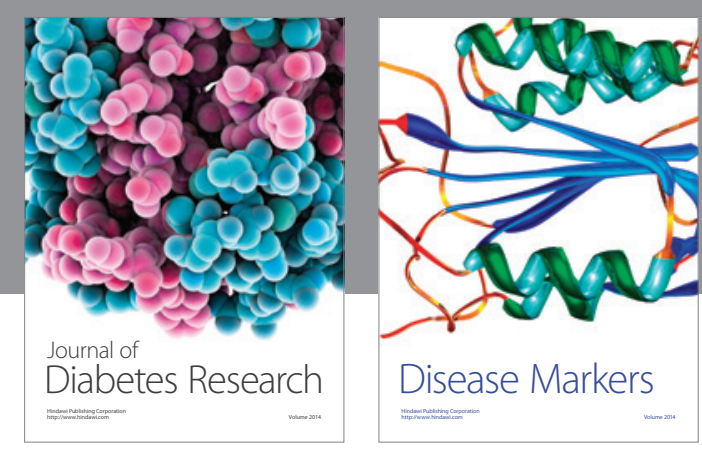

Disease Markers
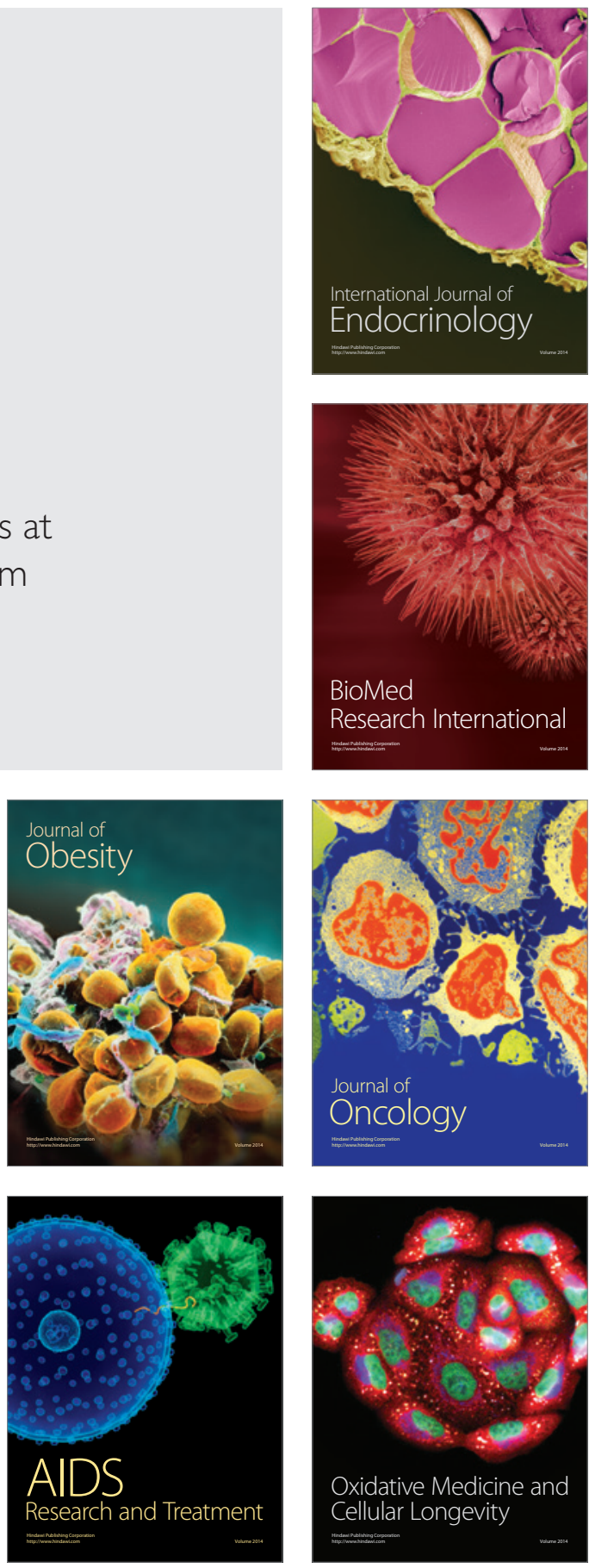